\title{
Investigating the stability of DNA-coated gold nanoparticles
}

\author{
Maria-Eleni Kyriazi ${ }^{\mathrm{a}}$, Antonios G. Kanaras ${ }^{\mathrm{a}, \mathrm{b}^{*}}$ \\ ${ }^{a}$ School of Physics and Astronomy, University of Southampton, Southampton, UK, SO17 1BJ \\ ${ }^{\mathrm{b}}$ Institute of Life Sciences, University of Southampton, Southampton, UK, SO17 1BJ
}

\begin{abstract}
In this paper we investigate how the density of oligonucleotides around spherical $15 \mathrm{~nm}$ gold nanoparticles (AuNPs) influences their stability against degradation by DNase I. We show that a significant decrease in the number of oligonucleotides attached to the AuNP surface is directly correlated with an increase in the DNA degradation by DNase I. Our experimental observations suggest that a close packing of oligonucleotides into a $3 \mathrm{~d}$ arrangement at the surface of AuNPs endows the probes with the necessary stability required for their use in intracellular applications.
\end{abstract}

Keywords: gold nanoparticles, DNaseI, oligonucleotides, cells

\section{INTRODUCTION}

In recent years, nanoscale particles that possess novel properties suitable for a range of biological and biomedical applications have been developed. ${ }^{1-4}$ Compared with other nanoparticles, AuNPs have been extensively used due to the progress in chemical methods to control their morphology, which results in the tunability of their optical and thermal properties. ${ }^{5-9}$ In particular, gold nanospheres (AuNSs) are broadly utilized in applications due to their fast and facile synthesis, low cytotoxicity and ease of bioconjugation. ${ }^{10}$ The surface of AuNPs can be readily modified with ligands containing groups, which bind to gold such as thiols, phosphines and amines. The ligand coating is essential for the stability of nanoparticles, for functionalization with active molecules and for manipulating their self-organization. ${ }^{2}, 11-15$ One of the most promising surface modification agents of AuNPs, especially for biomedical applications, is DNA. ${ }^{16-18}$ An important property of AuNP-DNA conjugates is their ability to bind complementary nucleic acids with a high affinity through Watson-Crick base pairing. ${ }^{1,2}$ In recent years this property has led to the development of probes to visualise and detect - in the live cell, at real time- cell to cell variations in messenger RNA (mRNA) expressions., ${ }^{19-26}$

Research groups led by Mirkin and Alivisatos were the first to report that spherical AuNPs could be functionalised with oligonucleotide strands. ${ }^{16,17}$ AuNPs functionalised with DNA have shown great promise as building blocks to form organized structures due to DNA's inherent specificity of molecular recognition. ${ }^{18,27-29}$ On the other hand, DNA-gold nanoparticles have also shown great potential and exciting opportunities for disease diagnostic and therapeutic treatment and used in gene regulation, drug delivery, cancer cell imaging and photothermal therapy. ${ }^{2,18,30,31}$

One of the inherent properties of DNA-coated AuNPs is the ability to traverse the charged cell membrane and enter a large variety of different cell types despite their polyanionic nature. By contrast, single or double stranded oligonucleotides of the same sequence usually require the use of lipid or cationic transfection agents in order to overcome the Coulombic repulsive forces between the cell membrane and the DNA phosphate backbone. ${ }^{32}$ However, one of the most important properties of DNA-coated AuNPs is there great intracellular stability and increased resistance towards degradation by nucleases. ${ }^{30,31,33}$

Research that involves the use of nucleic acids in biological environments is often hindered by the process of enzymatic hydrolysis, which leads to their degradation and renders them inactive. ${ }^{34}$ DNA-coated AuNPs have shown an increased resistance to nucleases such as DNaseI. This increased resistance is thought to be due to the close packing of oligonucleotides on the gold nanoparticle surface, which results in steric inhibition of enzyme binding. ${ }^{35,36}$ On the other hand, molecular DNA, treated to the same incubation conditions, shows no stability towards degradation.

In this paper, we show that the number of oligonucleotides attached to the AuNP surface is critical to the inhibition of DNA degradation by DNaseI. By gradually decreasing the DNA density we find that there is a concomitant increase in the percentage of DNA degradation. We therefore show that the DNA density on the nanoparticle surface is an important 
factor that governs the stability and function of DNA-gold nanoparticles and should be carefully considered as an important design parameter for the synthesis of DNA-coated gold nanoparticles to be used for cellular applications.

\section{MATERIALS AND METHODS}

\subsection{Materials}

All reagents were purchased from the following suppliers throughout and used without further purification: Sodium tetrachloroaurate (III) dehydrate, trisodium citrate, Bis(p-sulfonatophenyl)phenyl phosphine dehydrate dipotassium salt (BSPP), acrylamide/bis-acrylamide ( $40 \%$ solution) and ammonium persulfate (APS) were purchased from Sigma Aldrich. DNaseI and N,N,N',N'-tetramethylethane-1,2-diamine (TEMED) was purchased from Fischer Scientific. All oligonucleotides were synthesised by ATDBio

\subsection{Synthesis of $15 \pm 1.5 \mathrm{~nm}$ AuNPs}

A sodium tetrachloroaurate $(1 \mathrm{~mL}, 100 \mathrm{mM})$ solution was brought to the boil whist stirring in $99 \mathrm{~mL}$ of Milli Q water. To this, a sodium citrate solution $(5 \mathrm{~mL}, 2 \% \mathrm{wt})$ was added, and the solution was stirred for 15 minutes. Then, the reaction mixture was left to cool down whilst stirring. Once room temperature was reached BSPP (42 mg in $2 \mathrm{~mL}$ of Milli-Q water) was added to the reaction mixture, which was left stirring overnight. Large aggregates were removed by filtering the solution through a 0.45 Millipore filter and a concentrated solution of sodium chloride ( $2 \mathrm{~mL})$ was added to the reaction mixture until a colour change from wine red to grey/blue was observed indicating particle precipitation. Particles were purified through two sets of centrifugation at 10,000 rpm and redispersed in $3 \mathrm{~mL}$ of Milli-Q water.

\subsection{Oligonucleotide coating}

In order to coat our gold nanoparticles with a defined number of oligonucleotides a "salt ageing" method was employed. ${ }^{18}$ Briefly, BSPP coated $15 \mathrm{~nm}$ gold DNA monoconjugates $(1 \mathrm{~mL}, 10 \mathrm{nM})$ in water were incubated with thiol modified DNA strands at different ratios to achieve different loading denisties $(3 \mu \mathrm{M}, 1.5 \mu \mathrm{M}, 0.5 \mu \mathrm{M}$ and $0.2 \mu \mathrm{M}$ and $0.1 \mu \mathrm{m}$ in $1 \mathrm{~mL}$ ) and the reaction mixture was left to shake for $24 \mathrm{~h}$. bis(p-sulfonatophenyl) phenylphosphine (BSPP ,10 $\mu \mathrm{L}, 1 \mathrm{mg} / 20 \mu \mathrm{L})$, phosphate buffer $(0.1 \mathrm{M}, \mathrm{pH} 7.4)$ and sodium dodecyl sulfate $(10 \%)$ were then added to the nanoparticles' solution to achieve final concentrations of $0.01 \mathrm{M}$ phosphate and $1 \%$ SDS respectively. A final salt concentration of $0.30 \mathrm{M}$ was achieved by 6 additions of a $\mathrm{NaCl}(2 \mathrm{M})$ solution over a period of $8 \mathrm{~h}$. When incubated with a decreased concentration of oligonucleotides $(0.5 \mu \mathrm{M}, 0.2 \mu \mathrm{M}$ and $0.1 \mu \mathrm{m})$ the final salt concentration achieved was $120 \mathrm{mM}$ over 6 consecutive additions in $8 \mathrm{~h}$. The resulting DNA-coated gold nanoparticles were purified by three steps of centrifugation $(16,400 \mathrm{rpm}, 20 \mathrm{~min})$ and were stored at $4{ }^{\circ} \mathrm{C}$ in a hybridisation buffer $(5 \mathrm{mM}$ phosphate buffer, $80 \mathrm{mM}$ $\mathrm{NaCl})$.

\subsection{Characterisation techniques}

\section{Agarose gel electrophoresis}

Gels were prepared by dissolving agarose $(1.75$ or $2 \%$ ) in $0.5 \times$ TBE. This was heated in a microwave for 5 minutes ensuring that the agarose has completely dissolved. The solution was subsequently poured into a gel cast and combs were inserted to create wells. After allowing to set (2h), the gel was placed in an electrophoretic chamber containing $0.5 \times$ TBE. Prior to inserting within the wells, samples were mixed with a solution of Ficoll (15\% in $3 \times$ TBE) in order to increase the density of the sample. The loaded samples were then electrophoresed at $10 \mathrm{~V} / \mathrm{cm}$ for approximately 50 minutes or until a clear separation between bands was visible.

\section{Polyacrylamide gel electrophoresis (PAGE)}

A $6 \%$ PAGE gel was prepared in a $70 \mathrm{~mL}$ volume. A solution containing a $40 \%$ acrylamide: bis-acrylamide (19:1) solution $(10.5 \mathrm{~mL})$ and $5 \times \mathrm{TBE}(14 \mathrm{~mL})$ was made up to $70 \mathrm{~mL}$ using Milli Q water. The polyacrylamide solution then was formed by the addition of an intiator $\left(560 \mu \mathrm{L}\right.$, amine persulfate) and a crosslinker $\left(56 \mu \mathrm{L}, \mathrm{N}, \mathrm{N}, \mathrm{N}^{\prime}, \mathrm{N}^{\prime}-\right.$ tetramethylethylenediamine). The solution was then immediately syringed into the glass construct and a comb was inserted to create the appropriate wells to hold the samples. The combs were then removed, the electrodes were connected to a power supply and the gel was run at $10 \mathrm{~W}$ for $1 \mathrm{~h}$ to fill the matrix pores with the buffer. The oligonucleotide sample samples $(50 \mu \mathrm{L})$ were mixed with a Ficoll solution $(15 \%$ in $3 \times \mathrm{TBE})$ and subsequently loaded into the wells of the gel. The loaded gel was run at $10 \mathrm{~W}$ for $1.5 \mathrm{~h}$. It was removed from the glass cast and stained in a SYBR Safe solution for 10 minutes prior to imaging on a blue tray in a Bio-Rad Gel Doc EZ System. 


\section{UV-Vis spectroscopy}

The concentration of gold colloid and oligonucleotide solutions was determined this way by monitoring the absorption maximum over a wavelength range of 200 to $800 \mathrm{~nm} .{ }^{37}$ Spectra were gathered using a black Low Volume Quartz Cuvette using a Cary $100 \mathrm{UV}$-vis spectrophotometer. For dilute samples and negligible scattering the concentration of the analysed solution was determined by using the Beer-Lambert equation.

\section{Transmission electron microscopy (TEM)}

Gold nanoparticles were visualised on a Hitachi H7000 transmission electron microscope (operating at an accelerating voltage of $75 \mathrm{kV})$. For sample preparation, a small amount $(10 \mu \mathrm{L})$ of the solution to be analyzed was deposited on a 400 mesh formvar coated copper grid and left to air dry overnight.

\section{Oligonucleotide Loading}

Oligonucleotide loading was determined via dissolution of the gold core. A solution of $\mathrm{KI} / \mathrm{I}_{2}$ (ratio of $\mathrm{I}_{2}$ to $\mathrm{KI}$ was 1:6) was slowly added ( $1 \mu \mathrm{L}$ per addition) to the DNA - coated AuNPs solution $(8.33 \mathrm{nM}, 120 \mu \mathrm{L})$. Successful gold core dissolution was determined by a change in colour from wine red to yellow. ${ }^{38}$

The solution was then made up to $1 \mathrm{~mL}$ using Milli Q water and loaded onto a NAP 10 desalting column. After the solution had entered the column it was eluted using Milli Q water $(1.5 \mathrm{~mL})$. The oligonucleotide O.D. was measured at $260 \mathrm{~nm}$ on a DeNovix DS - 11 spectrophotometer. This value together with the initial O.D. of the oligonucleotide solution synthesised by Dr. Afaf El-Sagheer allowed for determination of the concentration and hence the number of moles of oligonucleotides in solution. Using this information we were then able to determine the exact number of oligonucleotide strands attached to the surface of each gold nanoparticle.

\section{Nuclease assay}

DNA coated gold nanoparticles $(150 \mu \mathrm{L}, 2.5 \mathrm{nM})$ in a solution containing Tris- $\mathrm{HCl}(10 \mathrm{mM}), \mathrm{MgCl}_{2}(2.5 \mathrm{mM})$ and $\mathrm{CaCl}_{2}(0.5 \mathrm{mM})$ at $\mathrm{pH} 7.4$ were incubated with DNaseI (from bovine pancreas, Sigma Aldrich, $2 \mathrm{U} / \mathrm{L}$ ). Samples were incubated overnight at $37^{\circ} \mathrm{C}$ and fluorescence measurements of the sense strand (FAM) were then taken during a $24 \mathrm{~h}$ period to determine the degree of degradation to the sense strands (excitation: $495 \mathrm{~nm}$, emission: $505 \mathrm{~nm}$ ). All experiments were performed in triplicates. Fluorescence measurements of all samples were performed on a Carry Eclipse Fluorescence spectrophotometer using a low volume quartz florescence cuvette.

\section{RESULTS AND DISCUSSION}

\subsection{Synthesis of AuNPs}

AuNPs can be quickly prepared in high quality and yield by a well-established protocol that was pioneered by $\mathrm{J}$. Turkevich and refined by G. Frens. ${ }^{39-41}$ This involves a reduction reaction between a gold salt $\left(\mathrm{NaAuCl}_{4}\right)$ and trisodium citrate. The reaction produces spherical AuNPs that are capped with citrate anions. In order to increase nanoparticle stability and to allow for their concentration by centrifugation, the labile citrate ligand was exchanged with BSPP. This was achieved via a ligand exchange where the phosphine readily displaces the loosely bound citrate due to an increased affinity towards the gold surface. A representative TEM image with the corresponding histogram is presented in Figure 1. 
A

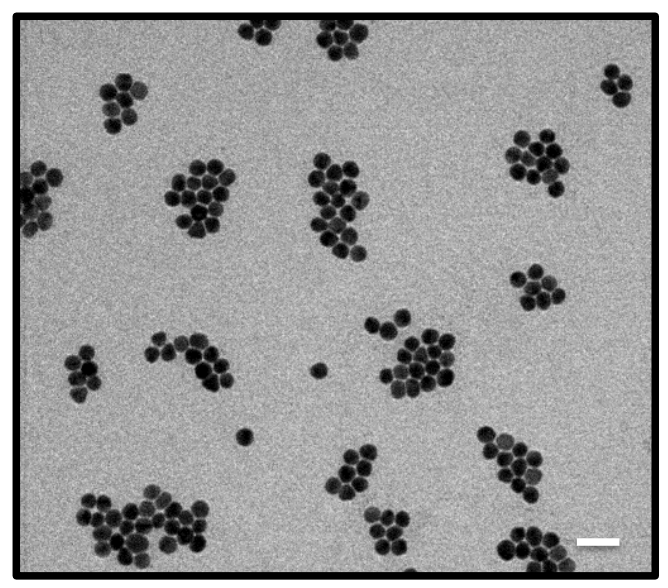

B

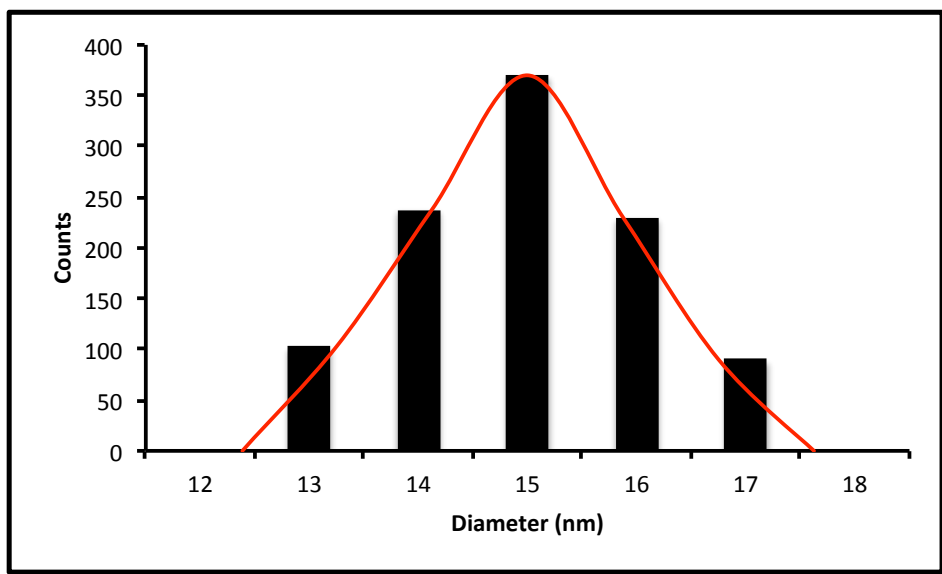

C

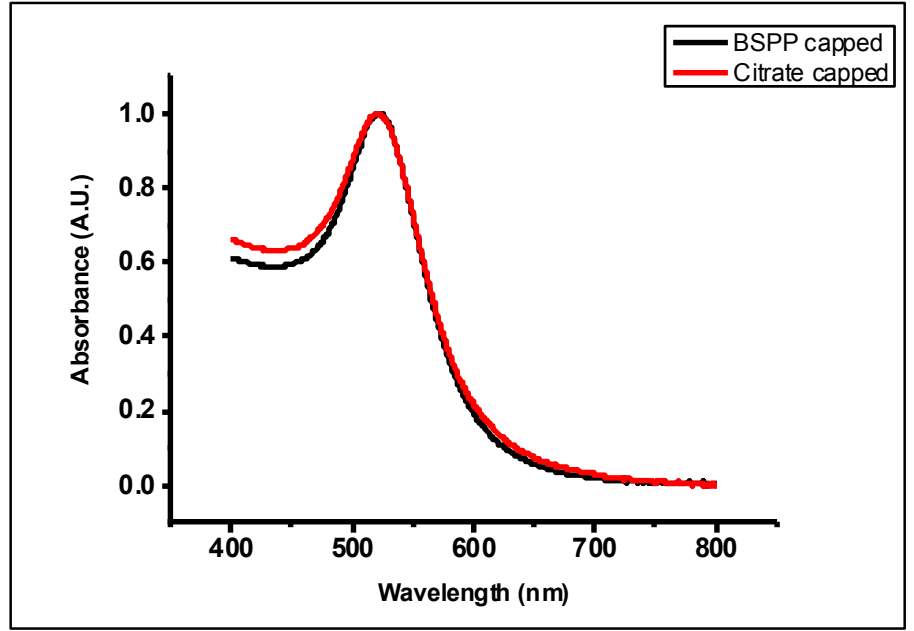

Figure 1: (A) TEM image of $15 \mathrm{~nm} \pm 1.4 \mathrm{~nm}$ AuNPs synthesized with the citrate reduction method. (B) Statistical analysis of AuNP diameter. (C) UV Vis spectra of citrate and BSPP coated AuNPs

As can be seen from the figure above, particles are monodisperse in size without any large aggregates present. These particles therefore, provide the ideal scaffold for the subsequent attachment of DNA to the gold nanoparticle surface.

\subsection{Oligonucleotide coating of AuNPs}

As mentioned earlier capping of a AuNP with DNA endows the particle with intracellular stability and increased resistance towards degradation by nucleases. Colloidal gold particles whose surface was modified with thiol capped synthetic DNA sequences were first co-discovered by Mirkin and Alivisatos in 1996. ${ }^{16,17}$ The difference between the two initially reported methods was the degree of oligonucleotide loading on the AuNPs. Whilst the Alivisatos group reported the functionalization with a defined number of DNA strands, the Mirkin group showed that the AuNP surface can be passivated with a large number oligonucleotide strands that can create a $3 \mathrm{~d}$ arrangement of oligonucleotides around the gold nanoparticle surface. ${ }^{18}$ 


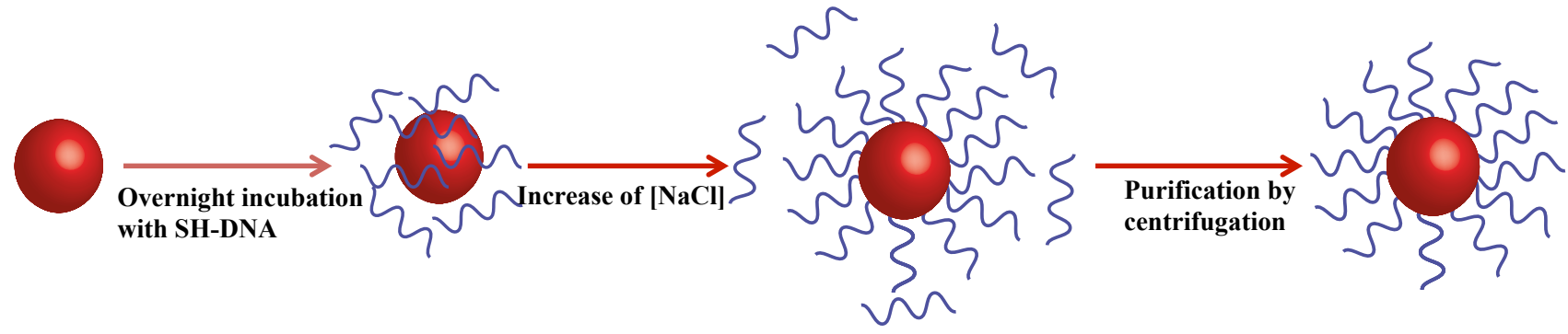

Figure 2: Method followed for multiple conjugation of SH-DNA strands to AuNPs

As shown in Figure 2 AuNPs are incubated with thiolated ssDNA overnight followed by a gradual (over $8 \mathrm{~h}$ ) increase in $\mathrm{NaCl}$ concentration. This slow 'salt ageing' process is required to screen repulsive negative charges between DNA phosphate backbones and the particle surface, thus ensuring a high oligonucleotide surface loading. It is also thought that the resulting high density of DNA inhibits the activity of DNaseI. Successful coating was confirmed by gel electrophoresis where the sample was run next to a sample of $15 \mathrm{~nm}$ BSPP-coated AuNPs.

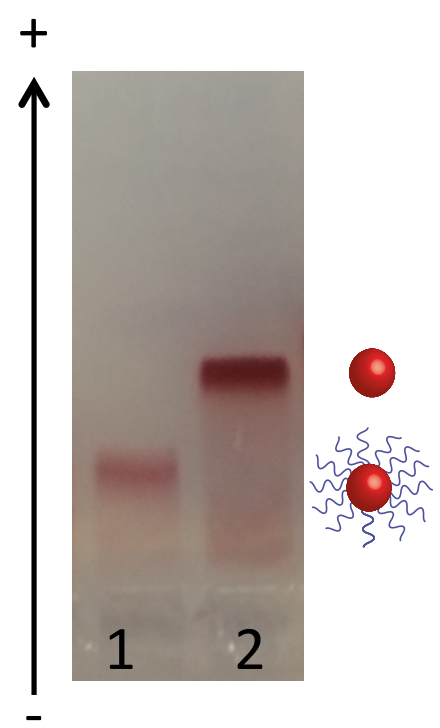

Figure 3: Separation of DNA: AuNP (15 nm) conjugates by gel electrophoresis. Lane 1: single BSPP coated gold nanoparticles Lane 2: DNA coated gold nanoparticles

A clear retardation of the band in lane 1 shown in Figure 3 proves that multiple conjugation of SH-DNA to AuNP was indeed successful. This delay is a combination of the increased size of the particle due to the large oligonucleotide shell as well as an increase in the negative charge of the structure due to the multiple negatively charged phosphate backbones.

\subsection{Modifying the oligonucleotide loading}

In order to assess the effect of oligonucleotide loading on the susceptibility of this system to degradation by DNaseI, we altered the number of oligonucleotide strands attached to the AuNP surface. To achieve a variety in DNA loading, a modified "salt ageing" method (see section 2.3) method was adopted where AuNPs were incubated with varied amounts of thiol-modified oligonucleotides. As we decreased the concentration of oligonucleotides in solution the number of bound oligonucleotides also decreased. To assess the degree of degradation, oligonucleotides were also modified with a 3' fluorescent dye (FAM). When attached to the AuNP surface the fluorescent dye is quenched however, upon degradation and oligonucleotide digestion the dye would no longer be found in close proximity to the AuNP surface, which would be determined via a concomitant increase in the fluorescent signature of the dye. 


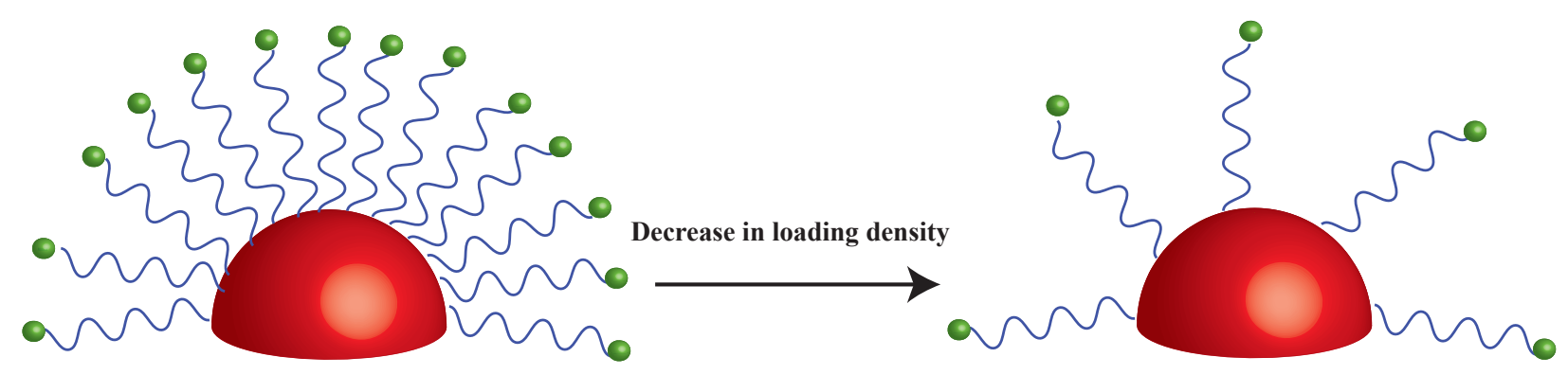

Figure 4: Decreasing the oligonucleotide loading by varying the DNA concentration in solution

In order to determine, in our system, the number of oligonucleotide strands attached per AuNP, the DNA-coated AuNPs were treated with a gold etching $\mathrm{KI} / \mathrm{I}_{2}$ solution to dissolve the gold core. The concentration of DNA in solution was determined by the fluorescence signature and it was used to calculate the exact number of oligonucleotides per gold nanoparticle.

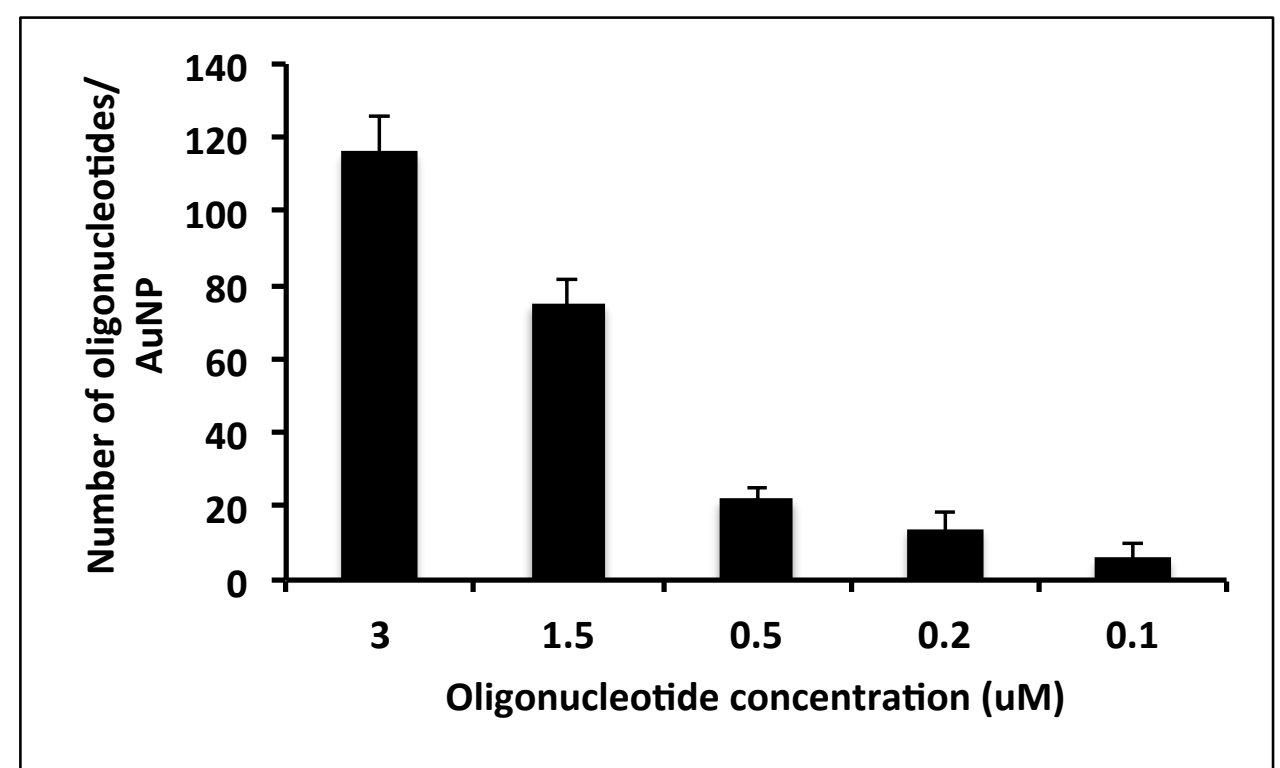

Figure 5: Number of oligonucleotides attached per gold nanoparticle with varying oligonucleotide and salt concentrations per reaction

As can be seen from Figure 5 as the concentration of oligonucleotides per reaction is decreased the total number attached to the AuNP surface also decreases. This diversity in surface coverage was used to assess how decreasing the loading density can affect DNA stability against the DNaseI enzyme.

\subsection{Nuclease assay}

As previously mentioned, one inherent complication with using oligonucleotide based probes for intracellular applications is their susceptibility to degradation by enzymes. DNaseI is an endonuclease, which is present within the cytoplasm and nonspecifically cleaves DNA by catalyzing the hydrolytic cleavage of the phosphodiester linkages in the DNA backbone. However, studies, have suggested that DNA-coated AuNPs with a shell of oligonucleotides ( 120 strands per $15 \mathrm{~nm}$ gold nanoparticle surface) show an increased stability towards digestion by nucleases due to the $3 \mathrm{~d}$ packed configuration of the oligonucleotides around the nanoparticle surface. 
To test if this hypothesis holds true, AuNPs coated with a dense shell of oligonucleotides (116 \pm 10 strands/AuNP) were incubated with DNaseI at $37{ }^{\circ} \mathrm{C}$ and the fluorescence from the sense strand was monitored for over a $24 \mathrm{~h}$ period. The corresponding data is depicted in Figure 6.

A

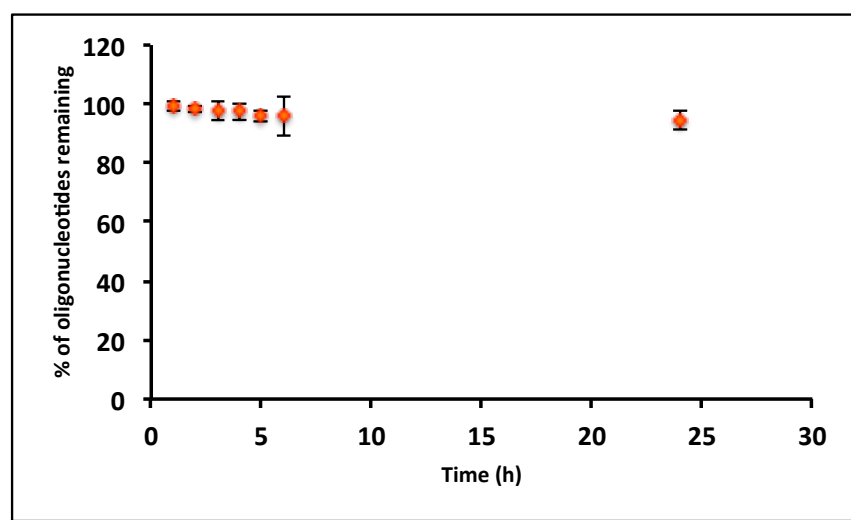

B

3

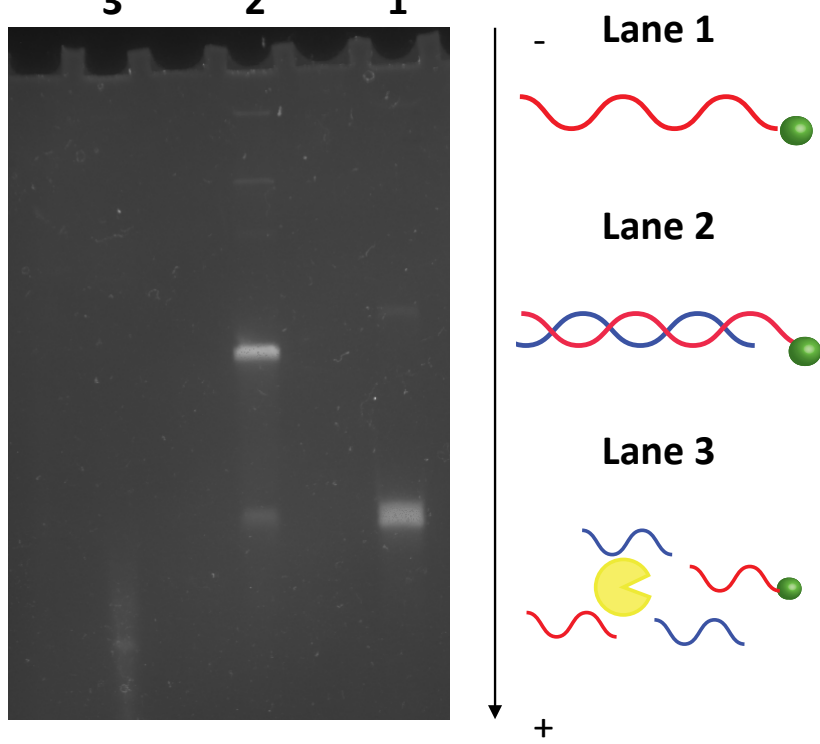

Figure 6: (A) graph showing the percentage of bound oligonucleotides over a $24 \mathrm{~h}$ incubation period with DNaseI. (B) PAGE gel displaying a single stranded DNA in Lane 1, double stranded DNA in Lane 2 and the degradation of a "free" DNA duplex in Lane 3

As can be seen from Figure 6 there is no significant degradation of the oligonucleotide shell around the AuNP. This was determined by monitoring the fluorescence signal from the fluorescent FAM dye modified oligos. As a comparison, a "non-bound" duplex of DNA was incubated with DNaseI under the same conditions and visualized using polyacrylamide gel electrophoresis. Lane 1 and 2 act as reference samples and represent single strands of oligonucleotides and double stranded DNA. In lane 3 only a very faint band is observed which represents double stranded DNA incubated with DNase I. This suggests that most of the duplex had been degraded into smaller fragments.

Having established that in comparison to "non-bound" DNA duplexes, DNA-AuNP conjugates show an increased stability towards DNaseI, we proceeded to investigate whether the number of oligonucleotides per AuNP can alter the observed stability. Four samples displaying a decreased surface coverage (see Figure 5) were treated under the same conditions with DNaseI and the fluorescence output from the FAM modified oligonucleotides was monitored over $24 \mathrm{~h}$. 


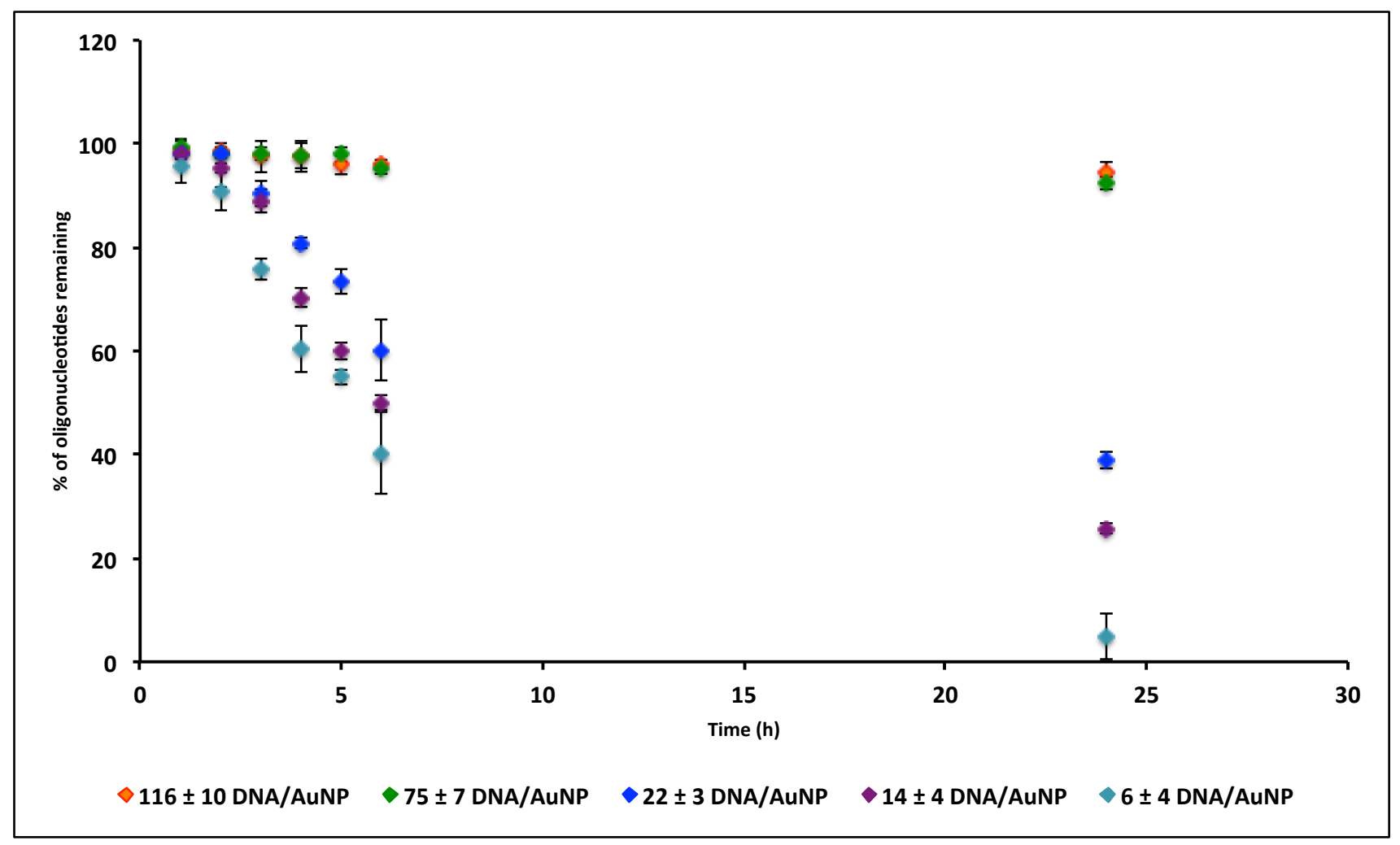

Figure 7: Graph showing the percentage of oligonucleotides remaining after a $24 \mathrm{~h}$ incubation period with DNaseI for the different loading densities achieved

As is evident from Figure 7 a general trend is observed where a decrease in the oligonucleotide loading on the AuNP surface leads to a concomitant decrease in the percentage of oligonucleotides that remain bound to the surface after $24 \mathrm{~h}$. However, when comparing the two highest loading densities the level of degradation is not considered to be significant and both have a similar percentage of oligonucleotides that remain bound to the surface. We could therefore consider the possibility that DNA-coated AuNPs display resistance to nuclease degradation over a range of oligonucleotide loading. Below this range the density of oligonucleotides are not sufficient to protect DNAs against digestion. Even though for a decreased number of oligonucleotides digestion is not complete within $24 \mathrm{~h}$, the continuous decreasing trend observed is an indication that for longer incubation times complete digestion would possibly be observed. It is therefore evident that nuclease resistance is highly dependent on the number of oligonucleotide strands that coat the AuNP surface. This could be due to the high steric hindrance that is created around the surface, which prevents DNaseI from digesting the surrounding oligonucleotides. As the DNA density is decreased and below a certain number steric hindrance is no longer prevalent and allows the gradual degradation of DNA. However, Mirkin and co-workers hypothesized that an increase in stability could also be due to high number of sodium ions being trapped between DNA strands on the surface. ${ }^{42,43}$ It has been found that the activity of DNaseI is highly reduced in the presence of a high concentration $(>0.1 \mathrm{M})$ of monovalent cations. ${ }^{2,44} \mathrm{We}$ can therefore hypothesize that a decrease in surface functionalization can also lead to a decrease in the concentration of sodium ion being trapped between strands thus allowing DNaseI to work more efficiently.

\section{CONCLUSION}

In conclusion we have shown that AuNP coated with a shell of oligonucleotides show an increased resistance towards degradation by DNaseI. However, this has been found to be the case for DNA-coated AuNPs that are coated with a large number of oligonucleotides ( 75 strands per AuNP). When the DNA density is decreased the oligos becomes susceptible to digestion and consequent degradation. This is therefore an important architectural property to consider when designing systems for intracellular applications. 


\section{ACKNOWLEDGMENTS}

The authors would like to thank the Leverhulme Trust for funding of this project (ref. RPG-2015-005). ATDBio is thanked for the supply of oligonucleotides.

\section{REFERENCES}

1. Heuer-Jungemann, A.; Harimech, P. K.; Brown, T.; Kanaras, A. G., Gold nanoparticles and fluorescentlylabelled DNA as a platform for biological sensing. Nanoscale 2013, 5 (20), 9503-9510.

2. Giljohann, D. A.; Seferos, D. S.; Daniel, W. L.; Massich, M. D.; Patel, P. C.; Mirkin, C. A., Gold Nanoparticles for Biology and Medicine. Angewandte Chemie-International Edition 2010, 49 (19), 3280-3294.

3. Chinen, A. B.; Guan, C. M.; Ferrer, J. R.; Barnaby, S. N.; Merkel, T. J.; Mirkin, C. A., Nanoparticle Probes for the Detection of Cancer Biomarkers, Cells, and Tissues by Fluorescence. Chemical Reviews 2015, 115 (19), 10530 10574.

4. Bio-Applications of Nanoparticles. Bio-Applications of Nanoparticles 2007, 620.

5. Quidant, R.; Louis, C.; Pluchery, O., Optical and Thermal Properties of Gold Nanoparticles for Biology and Medicine. Gold Nanoparticles for Physics, Chemistry and Biology 2012, 273-298.

6. Myroshnychenko, V.; Rodriguez-Fernandez, J.; Pastoriza-Santos, I.; Funston, A. M.; Novo, C.; Mulvaney, P.; Liz-Marzan, L. M.; Garcia de Abajo, F. J., Modelling the optical response of gold nanoparticles. Chemical Society Reviews 2008, 37 (9), 1792-1805.

7. Shenashen, M. A.; El-Safty, S. A.; Elshehy, E. A., Synthesis, Morphological Control, and Properties of Silver Nanoparticles in Potential Applications. Particle \& Particle Systems Characterization 2014, 31 (3), $293-316$.

8. $\quad$ Espinosa, A.; Di Corato, R.; Kolosnjaj-Tabi, J.; Flaud, P.; Pellegrino, T.; Wilhelm, C., Duality of Iron Oxide Nanoparticles in Cancer Therapy: Amplification of Heating Efficiency by Magnetic Hyperthermia and Photothermal Bimodal Treatment. Acs Nano 2016, 10 (2), 2436-2446.

9. Day, H. A.; Bartczak, D.; Fairbairn, N.; McGuire, E.; Ardakani, M.; Porter, A. E.; Kanaras, A. G., Controlling the three-dimensional morphology of nanocrystals. Crystengcomm 2010, 12 (12), 4312-4316.

10. Huang, X.; Jain, P. K.; El-Sayed, I. H.; El-Sayed, M. A., Gold nanoparticles: interesting optical properties and recent applications in cancer diagnostic and therapy. Nanomedicine 2007, 2 (5), 681-693.

11. Li, F.; Zhang, H.; Dever, B.; Li, X.-F.; Le, X. C., Thermal Stability of DNA Functionalized Gold Nanoparticles. Bioconjugate Chemistry 2013, 24 (11), 1790-1797.

12. Bartczak, D.; Kanaras, A. G., Diacetylene-Containing Ligand As a New Capping Agent for the Preparation of Water-Soluble Colloidal Nanoparticles of Remarkable Stability. Langmuir 2010, 26 (10), 7072-7077.

13. Baranov, D.; Manna, L.; Kanaras, A. G., Chemically induced self-assembly of spherical and anisotropic inorganic nanocrystals. Journal of Materials Chemistry 2011, 21 (42), 16694-16703.

14. Fernandes, R.; Li, M.; Dujardin, E.; Mann, S.; Kanaras, A. G., Ligand-mediated self-assembly of polymerenveloped gold nanoparticle chains and networks. Chemical Communications 2010, 46 (40), 7602-7604.

15. Coomber, D.; Bartczak, D.; Gerrard, S. R.; Tyas, S.; Kanaras, A. G.; Stulz, E., Programmed Assembly of Peptide-Functionalized Gold Nanoparticles on DNA Templates. Langmuir 2010, 26 (17), 13760-13762.

16. Alivisatos, A. P.; Johnsson, K. P.; Peng, X. G.; Wilson, T. E.; Loweth, C. J.; Bruchez, M. P.; Schultz, P. G., Organization of 'nanocrystal molecules' using DNA. Nature 1996, 382 (6592), 609-611.

17. Mirkin, C. A.; Letsinger, R. L.; Mucic, R. C.; Storhoff, J. J., A DNA-based method for rationally assembling nanoparticles into macroscopic materials. Nature 1996, 382 (6592), 607-609.

18. Cutler, J. I.; Auyeung, E.; Mirkin, C. A., Spherical Nucleic Acids. Journal of the American Chemical Society 2012, 134 (3), 1376-1391.

19. Prigodich, A. E.; Seferos, D. S.; Massich, M. D.; Giljohann, D. A.; Lane, B. C.; Mirkin, C. A., Nano-flares for mRNA Regulation and Detection. Acs Nano 2009, 3 (8), 2147-2152.

20. Seferos, D. S.; Giljohann, D. A.; Hill, H. D.; Prigodich, A. E.; Mirkin, C. A., Nano-flares: Probes for transfection and mRNA detection in living cells. Journal of the American Chemical Society 2007, 129 (50), 15477-+.

21. Pan, W.; Zhang, T.; Yang, H.; Diao, W.; Li, N.; Tang, B., Multiplexed Detection and Imaging of Intracellular mRNAs Using a Four-Color Nanoprobe. Analytical Chemistry 2013, 85 (21), 10581-10588.

22. Li, N.; Chang, C.; Pan, W.; Tang, B., A Multicolor Nanoprobe for Detection and Imaging of Tumor-Related mRNAs in Living Cells. Angewandte Chemie-International Edition 2012, 51 (30), 7426-7430. 
23. Prigodich, A. E.; Randeria, P. S.; Briley, W. E.; Kim, N. J.; Daniel, W. L.; Giljohann, D. A.; Mirkin, C. A., Multiplexed Nanoflares: mRNA Detection in Live Cells. Analytical Chemistry 2012, 84 (4), 2062-2066.

24. Zheng, D.; Seferos, D. S.; Giljohann, D. A.; Patel, P. C.; Mirkin, C. A., Aptamer Nano-flares for Molecular Detection in Living Cells. Nano Letters 2009, 9 (9), 3258-3261.

25. Halo, T. L.; McMahon, K. M.; Angeloni, N. L.; Xu, Y.; Wang, W.; Chinen, A. B.; Malin, D.; Strekalova, E.; Cryns, V. L.; Cheng, C.; Mirkin, C. A.; Thaxton, C. S., NanoFlares for the detection, isolation, and culture of live tumor cells from human blood. Proceedings of the National Academy of Sciences of the United States of America 2014, 111 (48), 17104-17109.

26. Xue, J.; Shan, L.; Chen, H.; Li, Y.; Zhu, H.; Deng, D.; Qian, Z.; Achilefu, S.; Gu, Y., Visual detection of STAT5B gene expression in living cell using the hairpin DNA modified gold nanoparticle beacon. Biosensors \& Bioelectronics 2013, 41, 71-77.

27. Nykypanchuk, D.; Maye, M. M.; van der Lelie, D.; Gang, O., DNA-guided crystallization of colloidal nanoparticles. Nature 2008, 451 (7178), 549-552.

28. Park, S. Y.; Lytton-Jean, A. K. R.; Lee, B.; Weigand, S.; Schatz, G. C.; Mirkin, C. A., DNA-programmable nanoparticle crystallization. Nature 2008, 451 (7178), 553-556.

29. Hurst, S. J.; Hill, H. D.; Mirkin, C. A., "Three-Dimensional Hybridization" with polyvalent DNA-gold nanoparticle conjugates. Journal of the American Chemical Society 2008, 130 (36), 12192-12200.

30. Wu, X. A.; Choi, C. H. J.; Zhang, C.; Hao, L.; Mirkin, C. A., Intracellular Fate of Spherical Nucleic Acid Nanoparticle Conjugates. Journal of the American Chemical Society 2014, 136 (21), 7726-7733.

31. Patel, P. C.; Giljohann, D. A.; Daniel, W. L.; Zheng, D.; Prigodich, A. E.; Mirkin, C. A., Scavenger Receptors Mediate Cellular Uptake of Polyvalent Oligonucleotide-Functionalized Gold Nanoparticles. Bioconjugate Chemistry 2010, 21 (12), 2250-2256.

32. Choi, C. H. J.; Hao, L.; Narayan, S. P.; Auyeung, E.; Mirkin, C. A., Mechanism for the endocytosis of spherical nucleic acid nanoparticle conjugates. Proceedings of the National Academy of Sciences of the United States of America 2013, 110 (19), 7625-7630.

33. Chung, C. H.; Kim, J. H.; Jung, J.; Chung, B. H., Nuclease-resistant DNA aptamer on gold nanoparticles for the simultaneous detection of $\mathrm{Pb} 2+$ and $\mathrm{Hg} 2+$ in human serum. Biosensors \& Bioelectronics 2013, 41, 827-832.

34. Mergny, J. L.; Boutorine, A. S.; Garestier, T.; Belloc, F.; Rougee, M.; Bulychev, N. V.; Koshkin, A. A.; Bourson, J.; Lebedev, A. V.; Valeur, B.; Thuong, N. T.; Helene, C., FLUORESCENCE ENERGY-TRANSFER AS A PROBE FOR NUCLEIC-ACID STRUCTURES AND SEQUENCES. Nucleic Acids Research 1994, 22 (6), $920-928$.

35. Barnaby, S. N.; Perelman, G. A.; Kohlstedt, K. L.; Chinen, A. B.; Schatz, G. C.; Mirkin, C. A., Design Considerations for RNA Spherical Nucleic Acids (SNAs). Bioconjugate Chemistry 2016, 27 (9), 2124-2131.

36. Rosi, N. L.; Giljohann, D. A.; Thaxton, C. S.; Lytton-Jean, A. K. R.; Han, M. S.; Mirkin, C. A., Oligonucleotide-modified gold nanoparticles for intracellular gene regulation. Science 2006, 312 (5776), 1027-1030.

37. Haiss, W.; Thanh, N. T. K.; Aveyard, J.; Fernig, D. G., Determination of size and concentration of gold nanoparticles from UV-Vis spectra. Analytical Chemistry 2007, 79 (11), 4215-4221.

38. Cho, E. C.; Xie, J. W.; Wurm, P. A.; Xia, Y. N., Understanding the Role of Surface Charges in Cellular Adsorption versus Internalization by Selectively Removing Gold Nanoparticles on the Cell Surface with a I-2/KI Etchant. Nano Letters 2009, 9 (3), 1080-1084.

39. Turkevich, J.; Stevenson, P. C.; Hillier, J., A study of the nucleation and growth processes in the synthesis of colloidal gold Discussions of the Faraday Society 1951, 11 (0), 20.

40. Turkevich, J.; Stevenson, P. C.; Hillier, J., The Formation of Colloidal Gold. The Journal of Physical Chemistry 1953, 57 (7), 3 .

41. Frens, G., Controlled nucleation for regulation of particle-size in monodisperse gold suspensions. NaturePhysical Science 1973, 241 (105), 20-22.

42. Kewalramani, S.; Zwanikken, J. W.; Macfarlane, R. J.; Leung, C. Y.; de la Cruz, M. O.; Mirkin, C. A.; Bedzyk, M. J., Counterion Distribution Surrounding Spherical Nucleic Acid-Au Nanoparticle Conjugates Probed by Small-Angle X-ray Scattering. Acs Nano 2013, 7 (12), 11301-11309.

43. Zwanikken, J. W.; Guo, P. J.; Mirkin, C. A.; de la Cruz, M. O., Local Ionic Environment around Polyvalent Nucleic Acid-Functionalized Nanoparticles. Journal of Physical Chemistry C 2011, 115 (33), 16368-16373.

44. Pan, C. Q.; Lazarus, R. A., Engineering hyperactive variants of human deoxyribonuclease I by altering its functional mechanism. Biochemistry 1997, 36 (22), 6624-6632. 